\title{
THE DECLINE OF ZOSTERA MARINA L. AT SALCOMBE AND ITS EFFECTS ON THE SHORE
}

\author{
By Douglas P. Wilson, D.Sc., F.R.P.S. \\ Zoologist at the Plymouth Laboratory
}

(Plates I-IV and Text-fig. I)

The history of the almost total disappearance of the eel-grass, Zostera marina L., from the Atlantic coasts of North America and a little later along the Atlantic coasts of Europe, in the early I930's, is fairly well known (for references see Butcher, I934 and Tutin, I938, I942), though the cause has never been satisfactorily determined. The symptoms of the 'wasting disease', with which it was stricken, are brown spots on the leaves which spread and darken until much of the leaf is covered, the leaf then becoming detached from the plant. Of the variety of factors to which this destruction of the living green tissues has been attributed a fungus, Ophiobolus halimus Mounce \& Diehl (Mounce \& Diehl, I934; Petersen, I935), and a species of Labyrinthula (Renn, I936; Young, I943) both rank high in probability as the chief causative agents. Atkins (1938) has strongly criticized the suggestion by Tutin (1938) that the fundamental cause of the epidemic was lack of sunshine in I93I-32 which led to enfeeblement of the plant with a lowering of its resistance to the parasites.

In the Plymouth district and at Salcombe a weakening of the growth of Zostera (locally known as 'gravit') was first noticed in the spring of 1932 . During the summer of that year very little Zostera could be obtained, and that consisted of short pieces. Blackening and rotting at the ends of the leaves was usual. At Salcombe there was a slight growth during the early autumn but it did not result in restoring the beds, or banks, to their old condition and it died down during the following winter. By early 1933 the Zostera banks at Salcombe were almost entirely devoid of green leaves and presented a blackish appearance, though here and there were small green patches due to a sparse growth of a few plants with leaves about a foot long. A few of these leaves, however, showed blackened and slightly rotted tips, for they still had the disease. These growing plants were situated at the edges of the old banks and seemed to be colonizing new areas of sand. The years that have passed since then have seen little or no extension of these patches, which for a time became even further reduced. Their present extent is discussed below.

Soon after the disease had reached Salcombe the appearance of the shore at the lowest levels exposed by spring tides was markedly changed. In the late I920's the mud flats north of the town, and the sandy muddy flats on each side 
of the harbour between the ferry and the rocks at the seaward end near Biddlehead and Fort Charles (see Text-fig. I), were green at low-water spring tides, so thickly did the Zostera cover them. Now there is little to be seen except grey mud above the town and shingly muddy sand and some seaweed below the ferry, for algae occupy some positions formerly covered with Zostera, especially on the south-east side between Small's Cove and Mill Bay, the area I know best of all. It is about this region of the harbour that I am here chiefly concerned, for I have followed its changes year by year, with the students' classes in the spring and when collecting polychaetes in the summer. Memory and notes are aided by old photographs; the latter are especially valuable in bringing to light changes in level which might otherwise have gone almost unnoticed. It seems well to publish some record of these changes whilst memories of past events are still fairly vivid, especially as the younger workers of to-day are almost unaware of the conditions that prevailed at Salcombe nearly twenty years ago.

The fauna of Salcombe was thoroughly investigated at the beginning of the present century by Allen \& Todd (I900). Much of this account still holds good: the rocks, the Salstone region, indeed any of the areas where Zostera did not flourish are not very different to-day than they were then. The Zostera areas were also much the same until I93I; after that, with the death of so many of the plants, changes set in. The first animals to become scarce were those whose habitat was the leaves of the Zostera itself; such species as Rissoa membranacea (J. Adams), Cantharidus striatus (L.) and Haliclystus auricula (Rathke). Some of these seemed to disappear entirely, for they have not, so far as is known, been taken in this locality since. For a time the roots and rhizomes, though dead, still bound the sand in the raised mounds so characteristic of Zostera beds. Even as late as 1935, when there was very little living Zostera to be seen, the mounds or banks were still more or less unchanged and the buried fauna revealed by digging was much as before. The eventual decay of the roots and rhizomes, which in the later stages were often dug up in a soft and blackened condition, loosened the sand and the tidal currents flattened the mounds and washed them away. The level of the shore fell and in some places the substratum became much more stony through a concentration of stones which had previously been much diluted with, or covered by, sand. Thus the character of the substratum was changed, making it less suitable for some species and more suitable for others, and certainly making it much harder to dig into. These changes in fauna and flora will be discussed later.

\section{The Disappearance of Banks near LoW-Water Mark}

Much of the following argument is based on comparisons of photographs taken on various dates at, or about, low water. It is necessary in making the comparisons to know fairly closely the actual heights with reference to chart 
datum of the water levels depicted. The level of low water can be obtained in the first place from the Admiralty Tide Table predictions, using those for Devonport, the nearest port for which predictions are available. The actual observed height of a tide, however, frequently does not coincide with the prediction, and I am therefore grateful to the Hydrographer to the Navy and his Department for supplying the necessary corrections for the tides referred to in this paper. The corrections for the 1926 and 1935 tides are based on comparison between observations and predictions at Devonport, but for the I 947 and I948 tides by comparison between observations and predictions at Newlyn. It is assumed that the Newlyn corrections apply closely to Devonport, the tidal range being very similar at both ports. It is assumed also that the tides at Salcombe follow the Devonport tides closely; the tidal range at Salcombe is very similar to that at Devonport. Thus the corrected levels for Devonport are here used to compare the water levels recorded in the photographs on the different dates. Throughout the paper all datum references are to Devonport. In the enclosed harbour of Salcombe the strength and direction of the wind probably has a greater influence on the water level than at Devonport, and therefore the weather at the time the photographs were taken is considered here. Whilst it is realized that this and other factors introduce some uncertainty into the comparison between water levels on different dates it is not believed that the main conclusions are substantially affected.

The photographs reproduced in Pl. I should now be examined. Fig. I gives a general view of the decaying Zostera banks looking north-east from Mill Bay on I8 July 1935 from approximately the position marked A in Text-fig. I. It must have been taken at or about low water, though the actual time was not recorded. On that date the Admiralty Tide Table predicted a low tide of ०.० ft., Admiralty chart datum, at Devonport, but observation showed that it was I.O ft. higher. In the photograph the ripples on the water and the direction in which the seagull faces both suggest a south-westerly breeze and this seems to be confirmed by the meteorological report for that day which records at Plymouth a south-west by west wind of Force 4 at I3.00 hr. G.M.T. At Salcombe such a wind would blow up the estuary, not down it. This breeze would tend to hold back the water draining from the estuary, thereby preventing the tide from falling to quite such a low level as it otherwise would have done. It is assumed, therefore, that at the time the photograph was obtained the water level was not less than I ft. above chart datum.

Fig. 2 is a photograph taken on 26 March 1948 from a position which is identical, or almost identical, with that from which fig. I was taken. This position for the second picture was obtained by careful sighting of landmarks shown in the first one. These are: first, the mast, chimneys and roofs of the buildings near the ferry landing, seen in the middle distance to the left centre of the picture, and the manner in which they align with the hedges of the fields on the hillside far behind them; secondly the alignment of a chimney on the 


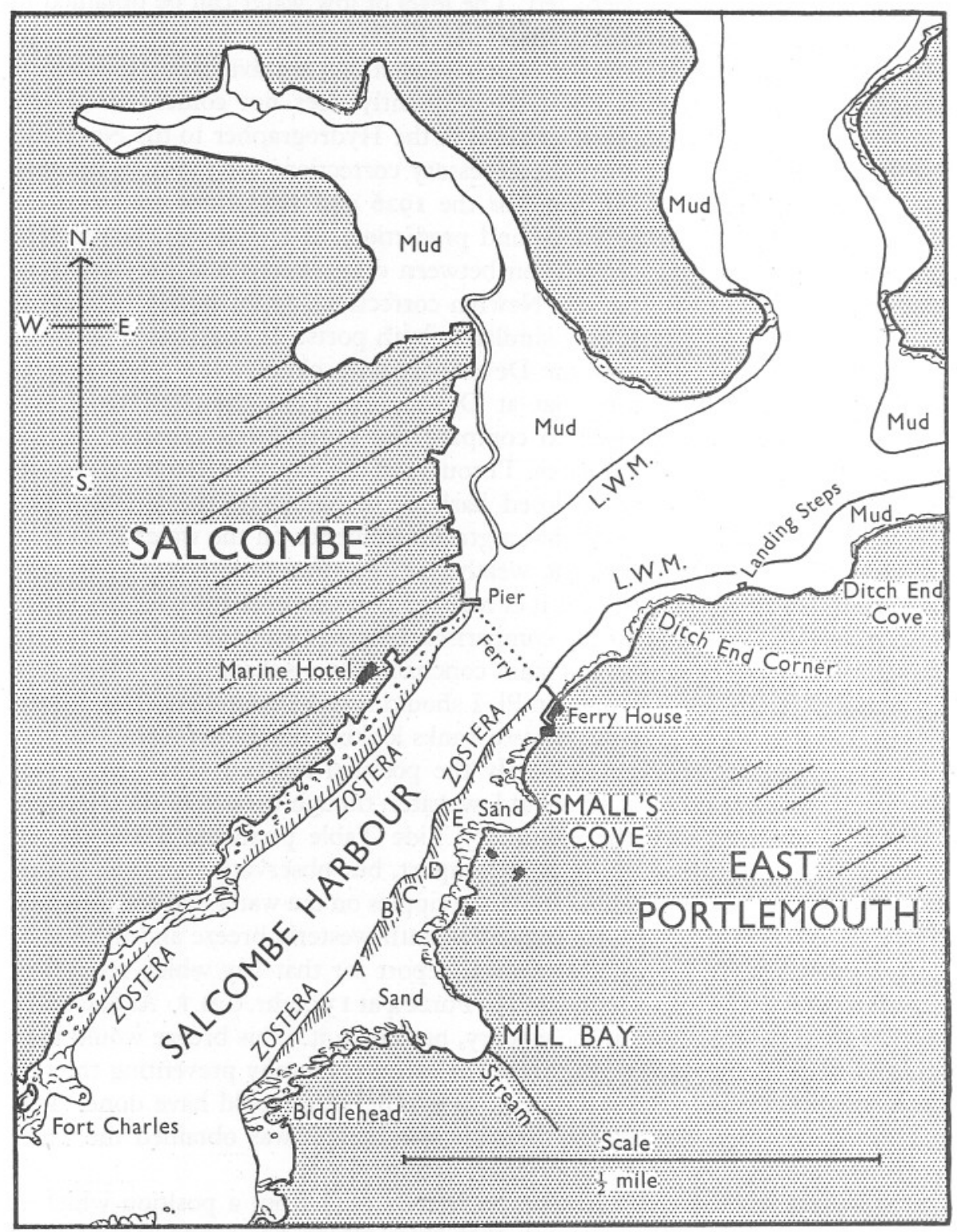

Text-fig. I. Sketch-map of Salcombe harbour and vicinity showing very approximately positions of Zostera beds (close hatched) on both sides below the ferry as they existed about 1926. Zostera also grew on the lower levels of the exposed mud above the ferry, but as the extent of the areas it covered is more doubtful they are not indicated. A, B, etc. mark the approximate positions from which the photographs reproduced in Pls. I-IV were taken, the camera always facing the Ferry House. A, Pl. I, figs. I, 2; B, Pl. II, fig. I; C, Pl. II, fig. 2; D, Pl. IV; E, Pl. III, figs. I, 2. 
lower of the two houses on the right with a corner and chimney of the house above and behind. These landmarks fix the position to within a yard, as was determined at the time the second photograph was obtained. On that occasion the distant hillside was slightly obscured by mist and hence is not so clearly rendered in the second photograph as in the first.

On 26 March 1948 the predicted low-water level was $\mathrm{I} \cdot 9 \mathrm{ft}$. below datum at Devonport. However, observation at Newlyn showed that there the tide was $2.5 \mathrm{ft}$. higher than the prediction. If we apply an equal correction to the Devonport prediction we assume that the level there was actually $0.6 \mathrm{ft}$. above datum. From this we can further assume that the Salcombe low water on that day was $0.4 \mathrm{ft}$. below low water of I8 July I935 and that there is at least this difference in the level of the water shown in the photographs, for whilst that of 26 March I948 was taken at dead low water that of I8 July I935 may have been taken a little before or after. However, on 26 March I948 a fresh breeze blew down the estuary towards the open sea; at Plymouth an east wind of Force 4 was recorded at I2.00 hr. G.M.T., an hour before low water at Salcombe. By I8.00 hr. G.M.T. the wind had increased to Force 5. This wind at Salcombe would have aided the outflowing tide and tended to depress, not raise, the level. At Newlyn the same wind (the Lizard record also shows an east wind of Force 4 at I2.00 hr. G.M.T.) would not have this effect but rather the reverse.

Certainly at Salcombe the tide exposed ground not often uncovered, and in the opinion of the local ferry men made 'a big out', an opinion with which our experienced collector, Mr William Searle, concurred. Thus in accepting the Newlyn correction as being applicable to Salcombe on this particular day we are more likely to be overcorrecting than otherwise, and it therefore seems reasonable to assume that the level of the water shown in Pl. I, fig. 2 is not only lower than that shown in fig. I, but is likely to be at least 6 in. lower and may well be lower still. If, for the purpose of what follows, this figure of 6 in. is taken, any estimated differences in ground level based on it can be regarded as minimal.

With these facts in mind the photographs may be compared. In the July I935 picture there is in the near distance a low mound whose seaward edge slopes fairly steeply down to the main channel. This mound of sand, bound by dead roots and rhizomes of Zostera, stretches into the distance beyond the lefthand boat stranded on top of it and as far as the figure in a white jersey. The steepness of the seaward slope can be judged by the bathers waist deep within a few yards of the edge and by the boat being rowed close inshore. (Details of bathers, oars of boat, etc., which are clearly visible in the original print, may not be discernible in the reproduction.) Very little living Zostera is to be seen, but the position chosen for this photograph includes a few plants in the foreground. A few also still grew in small patches here and there on the mound, whose greater area was, however, bare. It may be noted now that at no time did the Zostera completely disappear, a little always being present-this matter will be considered later on. 
The photograph of March 1948 shows a very different state of affairs. Where the mound previously existed there is now only water. The whole of the sandy foreground in Fig. I has been washed away and the change is strikingly evident if a comparison be made of the conditions around the site of the cross marked on each photograph to indicate the position from which the photograph reproduced in Pl. II, fig. 2, was taken a few minutes earlier. The water covering the site of the former mound was about a foot deep, in some places deeper, and this, it should be remembered, with what was almost certainly a lower tide; the general ground level must therefore be lower by $2 \mathrm{ft}$., perhaps even $3 \mathrm{ft}$. The 1935 photograph was taken from a tripod set on sandy ground above water level, whereas to obtain the 1948 photograph from the same position I was forced to wade almost up to the knees in water, again a difference in ground level of 2 or $3 \mathrm{ft}$. The slope to the main channel in 1948 is irregular but on the whole less sudden and steep than in 1935, at least at the water's edge, for it deepens again farther out. Collectors of to-day have less ground to work over than in I935, and it needs a lower tide than before to get on to what is left.

A few words of explanation about the piles which appear in the 1948 picture are needed. They formed the seaward extension of a repair base for damaged landing craft which was built in Mill Bay by United States forces during the war. Apparently the craft were brought in between the two groups of piles and hauled up a slipway the lower end of which may be seen as a dark line on the right of the photograph. The base occupied a portion of the north-east side of Mill Bay; it is now derelict, an ugly eyesore in a lovely setting. There is no reason to suppose that the existence of this base has had any material effect on the sandbanks of the lower levels, changes in which were very marked before the Americans came. Moreover, these changes have occurred over a very much wider area than that affected by the activities of the base.

So far, levels in 1935 have been compared with levels in March I948, but it is possible to go back another nine years. When in March 1926 a class in marine biology conducted by $\mathrm{Dr}$ (now Prof.) J. H. Orton at Plymouth was taken one day to Salcombe, I obtained the photograph reproduced in Pl. II, fig. I. The collectors are busy on the steep seaward edge of a Zostera bed in the heyday of its development. The thick covering of plants is clearly seen and it should be remembered that the growth would be thicker still in the summer. The steep slope at the seaward edge is even more strongly marked than in the I935 photograph when the beds were already beginning to disintegrate. This steep slope is very evident on the well-developed beds in the middle distance as well as in the foreground, in spite of the poor quality of the camera lens whose definition at the sides and in the distance left much to be desired. Nevertheless, landmarks are sufficiently clear for the camera position to be determined, and on 26 March 1948 an attempt was made to reach the same viewpoint (B in Text-fig. I). The landmarks used were the same or similar to 
those already described during the comparison of the photographs in Pl. I. The mast and buildings near the ferry landing and their parallax with the hedges of the hillside behind them fixed the position in one direction, whilst the tall white mast on the right and the gable of the house close by gave another. It is true that the gable in the 1926 photograph is partly obscured by trees since cut down but its position can be made out. As it happened, however, I was unable to reach the proper position, for after wading half-way up to the knees in water at the lowest ebb of the tide the ground began to drop away fairly steeply and I was unable to get out farther without flooding my rubber knee-high boots. I judged that in the true position I should be well over the knees in water and the camera held at eye-level would have been lower than the waist-level camera of I926. Thus the photograph reproduced in Pl. II, fig. 2 was actually taken several feet landward of the 1926 position and closer, along the same straight line, to the house and flag-pole on the right (position $\mathrm{C}$ in Text-fig. I). This landward position has resulted in the amount of shore exposed in the middle distance being apparently greater in 1948 than in I926, but a consideration of the difference in viewpoints will show that this idea is erroneous. The viewpoint of 1948 must have been close to the cross marked on the 1926 photograph, and this same viewpoint is marked, as we have already seen, on the photographs in Pl. I. Actually the seaward edge of the shore at low-water mark extreme spring tides is not very much changed for the area shown in Pl. II, fig. 2, though it is a little nearer the land on the whole than before, but the ground is lower and it takes a lower tide to uncover it than it did. It is this part of the shore that is so much more stony than it was years ago. The large Zostera bank in the foreground of the 1926 photograph has completely disappeared and the level here must have dropped 2 or $3 \mathrm{ft}$. This bed in dead and dying condition was still in existence in 1935, for it was none other than the low mound in the near distance seen in Pl. I, fig. I. That this is so is immediately apparent when it is remembered that the cross on that photograph and the cross on Pl. II, fig. I, both indicate the same position as closely as can now be determined.

So far the tidal level of the 1926 photograph has not been considered. The picture most probably was obtained on 16 March for which the tidal prediction was $\mathrm{I} \cdot 7 \mathrm{ft}$. below datum, but the observed height at Devonport was actually only $0.7 \mathrm{ft}$. below datum. The prediction for the previous day's tide had been a little lower but the class on that day was definitely not at Salcombe. No other tide in March I926 was predicted as low or lower than that on I6th. For that day the weather report records a light westerly breeze of Force 2 and it will be seen that the water in the picture is but lightly rippled. This breeze would scarcely affect the water level which can, therefore, be assumed to have been about a foot lower than that seen in the 26 March I 948 photographs (Pl. I, fig. 2, and Pl. II, fig. 2-but see remark concerning this day's wind, on p. 399), and was lower than in the photograph taken in July I935 (Pl. I, fig. I). 
The extensive Zostera banks which previously existed on the west side of the harbour, under the Marine Hotel and extending towards the harbour mouth, have similarly disappeared, and only a few sparse patches of Zostera remain. These banks were much more muddy than those on the east side and there were variations in the fauna to correspond. My visits to the west side have been less frequent than to the eastern shore and no photographs showing past conditions have been traced. Mr William Searle ('Bill'), the Laboratory's veteran collector, who has regularly worked under the Marine Hotel, informs me that the ground where the Zostera banks formerly existed is more stony and more difficult to dig into than the banks themselves used to be, and there is no longer a seaward edge where the ground suddenly sloped steeply downwards. To-day the collecting ground is uncovered by the tide for a shorter period than before, and with the tide at its lowest the water's edge is closer inshore.

It seems certain that the Zostera beds on this western side, south of the Marine Hotel, were considerably broader than indicated on the sketch map (Text-fig. I), extending out beyond low water spring tides, as they do to-day.

\section{The Accumulation of Sand near High-Water Mark}

A consideration of four photographs has shown that the ground near lowwater mark, on the east shore, has been lowered $2 \mathrm{ft}$. or more since most of the Zostera died, and the question now arises as to what has become of the sand which has been washed away. This question is answered, apparently, by a comparison of two more photographs which will now be considered.

The photograph of the north-west corner of Small's Cove reproduced in P1. III, fig. I, was taken in 1926 on the same day as that in Pl. II, fig. I. On 2I May 1947 the photograph shown in P1. III, fig. 2, was taken from the same viewpoint ( $\mathrm{E}$ in Text-fig. I), obtained by getting the lower left-hand buildings by the ferry slip in the same alignment with the distant hillside as shown in the earlier photograph. It was found that a very small displacement was sufficient to give appreciable parallax, and it can therefore be asserted with confidence that the camera in 1947 occupied a position in space almost identical with that of the camera of 1926, and that any variation could not have exceeded more than a few inches in any direction. The 1947 photograph was taken $\mathrm{I} \frac{1}{2} \mathrm{hr}$. before low water; the tide when the 1926 photograph was obtained seems to have been a little lower. Differences in definition between the photographs are due partly to different atmospheric conditions and to the much better lens used in I947.

Two features shown by the photographs call for first comment. The high jetty seen at the ferry landing in I947 was not in existence in I926. The end section of the drain pipe, so conspicuous in I926, was accidentally broken off at a later date but the remainder of the pipe, which I am assured has not been repaired or rebuilt, had by 1947 disappeared under a covering of sand and it is still so buried to-day. The natural rocks, however, show most clearly the rise 
in sand level, for it is plainly evident that in 1947 the sand was much more banked up at the foot of the cliff than in I926, especially on the right towards high-water mark, the rise being some 3 or $4 \mathrm{ft}$. In the 1926 photograph highwater mark spring tides is out of sight beyond the right-hand edge of the picture, but in the I 947 photograph a thin dark line of stranded weed stretches from the right-hand edge to the cliff rocks near the centre of the picture and marks the highest level reached by the previous high tide, a moderately high spring. The tongue of dark fucus-covered rocks near half-tide mark in the middle distance was more submerged by sand in 1947 than in 1926 and it is obvious that the sand beyond them, towards the ferry house, had also been banked up. At the top of this little bay, out of sight beyond the right-hand edge of these photographs, sand has been steadily accumulating year by year, raising the height of the beach near high-water mark, until an appreciable area is no longer inundated by spring tides. At that place I have watched with interest the slow but steady formation of a small sand dune colonized by Honckenya peploides Ehrb. and maritime grasses (Festuca, Agropyrum). The sand level is much the same to-day (December I948) as it was in May I947.

Sand has also accumulated in the upper part of the larger Mill Bay, but of this I have no definite records of my own. I am much indebted, however, to local inhabitants for various information, particularly to $\mathrm{Mr}$ and $\mathrm{Mrs} \mathrm{R}$. C. Tyler who, since I9I6, have occupied the house next to the ferry landing on the East Portlemouth side, and to Mr Harry Cook and son, boatmen of Salcombe. They all agree that sand began to accumulate on the east side of the harbour at least as early as I920, long before there was any reduction in the growth of the Zostera. This accumulation steadily increased and still goes on. Material washed and blown up from the old Zostera mounds therefore does not by itself fully account for the banking up of the sand on the higher shore levels; it has merely added to a process due to other causes. These causes lie outside the scope of the present paper, but it is worth recording that Salcombe was formerly much visited by sailing vessels which took away from Mill Bay large quantities of sand for ballast. Sand for building purposes was also removed in barges to Kingsbridge; according to Mr Harry Cook hardly a day went by without one or more barges visiting Mill Bay for this purpose. During the early years of the present century this traffic decreased and the last barge load for Kingsbridge was taken, so I am informed, shortly after the end of the I9I4-I8 war. About this time the high tide reached a wall by the roadway at the inner end of Mill Bay; but to-day this wall is silted over and the high-tide mark is about half-way down the bay.

The removal of so much sand in years gone by must have kept the level down-assuming that sand was accumulating all the time-and it seems therefore reasonable to suppose that the present silting may in some measure be due to the cessation of these activities. It should be noted that at the time this sand was being taken there were extensive Zostera beds on both sides of 
the harbour; some description of these will be found in Allen \& Todd (I900).

On the eastern shore the sand in general drifts to the north-east (prevailing winds come from points between south and north-west), and at the present time is piling up, especially on the rocks at Ditch End Corner, north-east of the ferry. It has turned the corner and has already travelled along the south shore as far as the old steamer landing steps just west of Ditch End Cove, covering muddy shingle and rocks.

It should be noted that in this sheltered harbour really big waves are not generated and the great transport of sand from one locality to another, such as is of common occurrence during stormy weather on exposed beaches like those of north Cornwall, is unlikely to take place. However, Mr Tyler told me that in a gale the sand banked up against the sea wall by the ferry house is sometimes washed away but it always comes back again, often on the next tide.

The sand slopes steeply down from high-water mark for most of the tidal range. It is loose, well drained and devoid of any obvious buried fauna. At the bottom of the slope the ground levels off, and in the firmer and wetter sand Arenicola, Lanice and other members of a normal sand fauna appear.

\section{The Efrect on the Fauna}

The death of the Zostera, and the consequent modification of the physical character of the areas it occupied, have had a noticeable effect on the fauna and flora. This has been most marked between Small's Cove and Mill Bay where the washing away of the sand has produced a stony ground with many of the stones exposed on the surface. This stony ground occupies a position where the most landward extensions of the Zostera lay; part indeed may not have been covered by Zostera at all. The stones give attachment to several species of algae, particularly Enteromorpha sp., Ulva sp., Fucus serratus Linn., Laminaria saccharina Lamour., and species of Ectocarpus, Ceramium, Polysiphonia, etc. Previously there had been growths of these seaweeds on a number of large stones which were scattered here and there, especially on this landward side of the Zostera beds, but the growths were nothing like as abundant as they are now. The photograph reproduced in Pl. IV shows the present seaw eed-covered stony area very well. It was taken on 2I May 1947, I5-20 min. after dead low water when the tide had risen $2-3$ in., as can be determined from anoth er photograph, not reproduced, which gives a closer view of part of the same region at dead low water. The Admiralty Tide Table prediction for that day gives low tide as being $0.7 \mathrm{ft}$. below datum, but the observ ed height at Newlyn was $2 \cdot 0 \mathrm{ft}$. above the prediction, from which we conclude that the water level when the exposure was made would be about $\mathrm{I} \cdot 5 \mathrm{ft}$. above datum. There was no wind. The viewpoint for this picture is indicated, approximately, by the cross on Pl. II, fig. 2 (when the tide was lower) and at D in Text-fig. I. The 
view includes the only Zostera bed visible on that day; on the picture a dotted line has been drawn around it. The Zostera extended a little way under water at the lowest ebb of the tide. In I948, conditions were still much the same as when this picture was obtained.

The extension of algal cover has very likely brought about an increase of animal life normally associated with stones and seaweed (e.g. Littorina littorea (L.), L. littoralis (L.), etc.), but no comparable figures exist and the surface fauna of this area has not been specially investigated. It appears to be much as would be expected in such a situation and it certainly lacks the interest of the specialized buried fauna for which this part of the Salcombe estuary has long been noteworthy. This is, of course, the remarkable and seemingly unmatched concentration of commensal animals in the ground on both sides of the harbour.

At the bottom of the slope down from Small's Cove there is still a large colony of Lanice conchilega (Pallas) and an abundance of Arenicola marina L. In the galleries of some of the Arenicola fairly large specimens of Harmothoë lunulata var. marphysae McIntosh may be found. Part of this area is uncovered in the near distance in Pl. III, fig. I. Zostera beds occupied the lower levels of this cove and stretched in a nearly continuous bank to Mill Bay ${ }^{1}$ and beyond (see Text-fig. I and Pl. II, fig. I). It was in this bank that Acrocnida brachiata (Montagu), with its commensals Mysella bidentata (Montagu) and small specimens of Harmothoë lunulata var. marphysae, were abundant. The brittlestar is still common in the stony soil, but is not as numerous as formerly and seems less frequently accompanied by its commensals which, since the war, have been appreciably more difficult to find with it. This may, of course, be merely a passing phase, but it seems hardly likely that the brittle-star will again reach its former abundance in ground less suitable for it. The ground itself is relatively barren and but few animals of any kind are found for much hard digging, for there has taken place a very marked diminution in the number of species and individuals turned up by the fork. Thus Phascolosoma elongatum Keferstein, with which was often Mysella bidentata, was formerly common but is now infrequently found, while Amphitrite edwardsi Quatrefages with its large handsome commensal Lepidasthenia argus Hodgson have become very rare. These two associated polychaetes were not uncommon, although always less numerous here than in the muddier opposite shore of the harbour where they are also less abundant than before. The synaptids, Leptosynapta inhaerens (O.F. Müller) and Labidoplax digitata (Montagu), and their commensals, were previously present in small numbers on the Mill Bay side but are now rarely turned up when digging, and the same remark applies to Upogebia deltaura Leach and U. stellata (Montagu), while Lepton squamosum (Montagu), an inhabitant of

1 The gap in the bed opposite Mill Bay, indicated in Text-fig. I, is seen in photographs taken in 1926 , and it forms the immediate foreground in Pl. I, fig. I. It may have been caused by the freshwater stream which ran down the beach and at low tide discharged through it. 
their burrows, has not been obtained here for several years. Callianassa subterranea (Montagu), always uncommon, is less frequently found than formerly, and this is true also of a number of other non-commensal species such as Owenia fusiformis Delle Chiaje and Notomastus latericeus Sars.

Towards Mill Bay, where there are still patches of sand with but few stones, Echinocardium cordatum (Pennant) and its commensal Montacuta ferruginosa (Montagu) are as common as ever, and some other inhabitants of clean sand such as Caesicirrus neglectus Arwidsson and one or two species of Magelona are also abundant. These species were always to be found here in the sand where Zostera did not grow, as well as occasionally in the beds themselves.

In this account no attempt is made to give a complete description of the buried fauna of the area under review, rather is it the intention to record the more obvious changes, or absence of change. The region is still of very considerable interest, but much of its former richness and diversity has been lost and this can be directly attributed to the physical changes following the disappearance of the Zostera. In my opinion overcollecting is not the cause. It would have been possible to overcollect on this shore but care was taken that this should not happen. During the war very little collecting was done ${ }^{1}$ (there were no students' classes at Plymouth during the years I94I-45 inclusive), but the fauna has shown no sign of recuperation, for, on the contrary, it was definitely poorer after the war than before. It has become more than ever necessary to avoid excessive digging over the smaller area now uncovered and it is sincerely to be hoped that future collectors will do their utmost to conserve what remains.

\section{The SURVIVING ZOSTERA}

There remains for consideration the Zostera itself. Of the three British species of Zostera there is only one likely to be confused with $Z$. marina. This is $Z$. Hornemanniana Tutin, which can grow from half-tide mark down to I-2 fathoms and it has been seen at Salcombe (Tutin, I936). The species is distinguished by the smaller stigmas relative to the length of the style and by the smaller seed (Tutin, 1938). It was thought necessary, therefore, to determine the species of the Zostera still growing in small quantity at Salcombe.

On I9 July 1947, during the flowering season, my wife aided me in going over all the Zostera we could find. On that day the small Zostera bed seen in the photograph on Pl. IV was not uncovered, the shallowest part being submerged by a few inches of water and most of it was covered by $6-9$ in. at the lowest ebb. Between us we managed to cover most of the ground and obtain flowers and seeds. Without exception the plants proved to be Z. marina L.

Although the specific identity of the Zostera at Salcombe is the same now

\footnotetext{
${ }^{1}$ A local informant tells me that Americans stationed at the repair base in Mill Bay collected for eating all the Ensis they could find. These were always most numerous near the south-west corner of Mill Bay. Ensis was certainly very scarce at that place in 1946 and 1947 but by 1948 small ones were again fairly plentiful.
} 
as it was always supposed to have been, I have a strong impression that presentday plants are shorter and a little narrower in the leaf than they used to be, and that they do not show as vigorous a growth. In this I am supported by the local people whose names have already been mentioned. It seems to be generally agreed that in the summer a length of 5 or $6 \mathrm{ft}$. was quite usual, though all plants did not attain these dimensions and they were longer in some parts of the estuary than in others. In July 1947 the tallest plants my wife and I could find did not exceed $3 \mathrm{ft}$. (about $90 \mathrm{~cm}$.) and most were considerably shorter. The breadth of their leaves was $\frac{1}{4}$ in. and less (approx. 5-7 mm.) and the colour a good bright green. On the longer leaves some epiphytic red algae were growing, as is usual; we did not see any Haliclystus. In the previous May the plants had been less than $2 \mathrm{ft}$. long (about $60 \mathrm{~cm}$.) and they had certainly not been longer than this in March. In March I 948 the tallest plants were only I 8 in. (about $46 \mathrm{~cm}$.) My memory assigns a length in March and April of 2-3 ft. to the longest leaves and Mr William Searle agrees with this. Prof. J. H. Orton writes 'my impression is that they might have been two feet about'. This would make them one and a half times or even twice their present length for that time of year. The plants in the photograph of March I926 (Pl. II, fig. I) look to have been of moderate length, and the appearance suggests that a good many exceeded the $\mathrm{I} 8$ in. maximum of March 1948 , though the definition is too poor for certainty on this point. Some photographs taken at low tide near Ditch End Cove in 1927 show quite distinctly that the plants there growing on sticky mud were only about 9 in. (or $23 \mathrm{~cm}$.) long, estimated with reference to a collecting basket also in the pictures. The time of year when they were taken is uncertain, but various indications point to January or February as the most likely months. There seems to be no Zostera at Ditch End now, and it was probably always shorter there than in the harbour below the ferry. There is, too, the possibility that it was Z. Hornemanniana (Tutin, I942), which seems to grow best on a soft mud substratum, a possibility that is increased when the widths of the leaves, seen in the photographs, are compared with the wickerwork of the collecting basket. The same type and make of basket is still in use and the thin canes of which it is woven have an average diameter of $3.5 \mathrm{~mm}$. with a variation either way of $0.5 \mathrm{~mm}$. The basket in the photographs has an almost identical number of strands and the same general dimensions as presentday ones, therefore its canes must have been of similar cross-section. Now the Zostera leaves appear distinctly narrower than the cane strands, and such measurements as are possible on the photograph confirm this impression. One of the characters of $Z$. Hornemanniana is that its leaves are only about $2 \mathrm{~mm}$. broad; those of $Z$. marina are mainly 5-10 mm. broad (Tutin, I942), although there is said to be a very narrow-leaved variety, Z. marina var. stenophylla Asch. \& Graebn. about which little definite information is available. In the photograph of the Zostera bed in Pl. II, fig. I, the leaves seem distinctly broader than the woven strands of the baskets, thus agreeing with normal $Z$. marina. 
If we accept a length of 2 or $3 \mathrm{ft}$. as the former length for Zostera marina in the Mill Bay region in March, it follows that a summer length of 5 or $6 \mathrm{ft}$. might very well have been attained. Summer Zostera obtained near Plymouth when trawling for pipe-fishes in the estuary of the River Yealm or in Cawsand Bay must have reached this length. It was the usual practice to tie bunches of this Zostera to stones which were then dropped into the pipe-fish tank in the aquarium. The tank is $3 \mathrm{ft}$. 4 in. deep, and I well remember how most of the leaves reached the surface and spread out floating horizontally for a foot or more, and this after some of the older and longer leaves most heavily covered with epiphytes had been removed. The Zostera in the River Yealm to-day is nothing like that length; there has been very little at all in Cawsand Bay for years, and what is there is short.

Whilst from the above considerations it seems quite definite that much of the $Z$. marina existing before the disease appeared had considerably longer leaves than any of the plants now living in the Plymouth district, it is more difficult to establish that the leaves were also wider. Most of those who remember the plants prior to 1930 , and whom I have questioned, agree that the leaves were wider than any seen at present and it has already been stated that that is my own impression. Some equally good observers, however, are not so certain. In the absence of specimens (I have not been able to trace any in herbaria $^{1}$ ) it is impossible to establish the truth, and the only photograph showing the leaves at all clearly is an old picture of pipe-fishes in one of the aquarium tanks among Zostera which had almost certainly come from the River Yealm. This photograph, made before I93I, is reproduced elsewhere (Wilson, I935, fig. 83). By comparing the widths of the leaves with the lengths of the heads of the pipe-fishes in the photograph an estimate of the actual widths can be made when the dimensions of the heads of the pipe-fishes are known. This can be closely determined from museum specimens of the same species. Simple calculations based on the smallest probable lengths of the heads of the pipe-fishes photographed give the widths of the most clearly defined leaves as being over $8 \mathrm{~mm}$.; this can be regarded as a conservative estimate. These leaves were thus considerably wider than any seen recently.

The conclusion that the leaves of Zostera were generally wider, as well as longer, is in agreement with earlier discussion on this subject (Blackburn, 1934; Cottam, 1935; Butcher, 1934, I935) before Z. Hornemanniana Tutin (1936) had been recognized. It seemed then generally agreed that the Zostera remaining on the beds was of narrower leaf than many of the plants had formerly been. It is well known that the stature of individual plants, terrestrial and aquatic, is much influenced by the environmental conditions under which they grow and it has been suggested (Cottam, 1935, 1938; and see also Setchell, 1929)

${ }_{1}$ Miss E. Pearse, Paignton, has very kindly sent me a dried specimen of $Z$. marina collected in Cawsand Bay in August I900. It has a length, exclusive of rhizome, of $3 \mathrm{ft} .4$ in. (about I m). and a leaf width of about $5 \mathrm{~mm}$. 
that the different forms of $Z$. marina are but an expression of a varying environment. But apart from the washing away of the sand of the old banks it seems improbable that the physical and chemical conditions of the River Yealm and Plymouth Sound, to mention only localities near this laboratory, have so changed in character that the plant can no longer form broad and lengthy leaves. The hydrographic changes known to have taken place in the western English Channel might have been suspected had the phenomenon been purely local, but it was not. Everywhere, or almost everywhere, it was the broad long-leaf form which suffered most severely, leaving narrow short-leaved forms of which one subsequently proved to be a hitherto unrecognized species, $Z$. Hornemanniana. It would be interesting to know whether the broad-leaved and formerly vigorously growing variety was a definite morphological or physiological strain, which in the event proved more susceptible to the disease than did other strains.

The Zostera at Salcombe is, I think, spreading slowly, very slowly. No measurements are available but my impression is that there is a little more present than in the years immediately before the war when there was very little to show to the students attending the annual classes held during the Easter Vacation. To-day rather more is to be seen; it should be carefully conserved and the temptation to dig into it resisted. If left alone it may in the years to come re-establish itself and its specialized fauna with it. Unhappily, brown patches on many of the leaves can still be found, indicating that the disease is still present. It is to be hoped that the disease will become less virulent, or that a strain of $Z$. marina vigorous in growth but with high resistance to disease will some day appear to repopulate the estuaries and other sheltered waters where this useful plant was formerly abundant. On the American coast a trend toward restoration of the plant in favourable areas has been reported by Cottam (I945).

\section{ACKNOWLEDGEMENTS}

Thanks are due to a number of people who have helped by providing information, or in other ways. I am especially indebted to Mr Harry Cook of Salcombe, $\mathrm{Mr}$ and Mrs R. C. Tyler of East Portlemouth, and the Salcombe ferry men, $\mathrm{Mr}$ V. H. Ford and Mr W. Jarvis, together with a number of local people whose names I do not know. Miss C. I. Dickinson provided me with data concerning specimens of Zostera in the Herbarium at the Royal Botanic Gardens, Kew, and Mr R. Ross did the same for the British Museum (Natural History) collection. The assistant curators of the Plymouth City Museum and the Royal Albert Museum Exeter and the curator of the Torquay Natural History Society's museum and various private individuals have given me access to herbaria in their care. Mr T. G. Tutin kindly examined some specimens for me and confirmed an identification. To my wife I am indebted for help with botanical identifications and for the photograph reproduced in 
P1. I, fig. I. Special acknowledgement is due to the Hydrographer to the Navy and his Department for tidal corrections for several dates. The Director, Mr F. S. Russell, has taken a kindly interest in this work throughout for which I am very grateful.

\section{SUMMARY}

A comparison of photographs taken on the eastern shore of Salcombe harbour before and after the disappearance of much of the Zostera marina L. shows that where previously there existed extensive sand banks, stabilized by the growth of this plant, there has been a lowering of ground level of $2 \mathrm{ft}$. or more, due to the washing away of the sand where the Zostera has died. Much of the ground is more stony than before and has become largely covered with seaweed attached to the stones. The buried fauna is not as rich as it was and some species previously common are rare or have disappeared altogether. A few small patches of Zostera still survive, but the plants are shorter with narrower leaves than before.

On the west side of the harbour there also seems to have been a similar drop in shore level at about low-water mark spring tides following the disappearance of much of the Zostera, and the buried fauna is also poorer than previously, but for this side no photographs and fewer data are available.

On the east side the sand washed away from the old Zostera banks has apparently been carried on to the higher levels to add to sand which has been steadily accumulating there for many years, especially near high-tide mark.

Plants of $Z$. marina now growing at Salcombe reach a height of about $3 \mathrm{ft}$. (about $90 \mathrm{~cm}$.) in summer and have a maximum leaf width of about $\frac{1}{4}$ in. $\left(5^{-7} \mathrm{~mm}.\right)$, whereas previously the plants were longer, possibly reaching 5 or $6 \mathrm{ft}$. (I50-180 cm.) and had wider leaves. Plants from the estuary of the River Yealm near Plymouth certainly reached a length of $5 \mathrm{ft}$. or more, prior to I93I, and a calculation from an old photograph indicates that their leaves attained a width of at least $8 \mathrm{~mm}$.

Old photographs of Zostera growing on soft mud near Ditch End Cove, above Salcombe harbour, show short very narrow-leaved plants which may have been $Z$. Hornemanniana Tutin.

\section{REFERENCES}

Allen, E. J. \& Todd, R. A., I900. The fauna of the Salcombe estuary. Fourn. Mar. Biol. Assoc., Vol. vi, pp. I5I-2I7.

Atkins, W. R. G., I938. The disappearance of Zostera marina. Fourn. Mar. Biol. Assoc., Vol. xxiII, pp. 207-Io.

BlackBURN, K. B., I934. Wasting disease of Zostera marina. Nature, Vol. cxxxiv, p. 738 .

ButCHER, R. W., I934. Zostera. Report on the present condition of eel grass on the coasts of England, based on a survey during August to October, 1933. Fourn. Cons. Perm. Internat. Explor. Mer, Vol. Ix, pp. 49-65.

- 1935. Wasting disease of Zostera marina. Nature, Vol. cxxxv, p. 545. 
Cotram, C., I935. Wasting disease of Zostera marina. Nature, Vol. cxxxv, p. 306.

1938. Status of eelgrass (Zostera marina) on the north Atlantic Coast, February 1938. U.S. Dep. Agr. Bur. Biol. Survey. Wildlife Research and Management Leaflet B.S. I Io.

- 1945. Eelgrass conditions along the Atlantic seaboard of North America. Plant Disease Reporter, Vol. xxIx, No. I2, pp. 302-IO.

Mounce, I. \& DieHL, W. W., I934. A new Ophiobolus on eelgrass. Can. Fourn. Res., Vol. XI, pp. 242-6.

Petersen, H. E., I935. Preliminary report on the disease of the eelgrass (Zostera marina L.). Rep. Danish Biol. Sta., Vol. xL, pp. 3-8.

Renn, C. E., I936. The wasting disease of Zostera marina. Biol. Bull. Woods Hole, Vol. Lxx, pp. $148-58$.

SetChell, W. A., I929. Morphological and phenological notes on Zostera marina L. Univ. Calif. Publ. Bot., Vol. I4, pp. 289-452.

Tutin, T. G., I936. New species of Zostera from Britain. Fourn. Bot., Vol. Lxxiv, pp. $227-30$.

1938. The autecology of Zostera marina in relation to its wasting disease. New Phytologist, Vol. xxxvII, pp. 50-71.

I 1942 . Biological Flora of the British Isles. Zostera L. Fourn. Ecology, Vol. 30, pp. $217-26$.

WILSON, D. P., 1935. Life of the Shore and Shallow Sea. London.

YounG, E. L. III, I943. Studies on Labyrinthula, the etiologic agent of the wasting disease of eel-grass. Amer. Fourn. Bot., Vol. 30, pp. 586-93.

\section{ADDENDA}

I

Since this paper went to press the following information has been received from Major Arthur A. Dorrien Smith, Tresco Abbey, Isles of Scilly, and this seems a suitable place to record it. He has kindly given permission for this to be done.

In the Isles of Scilly Zostera marina was formerly abundant, covering hundreds of acres of tidal flats between the Islands, but now in I949 scarcely any remains. The eel-grass died away about the same time as at Salcombe and elsewhere round the British coast. After its death the mud in which it grew, and which was bound by its roots and rhizomes, was loosened and washed away leaving behind nothing but sand. The drift of the tide has carried the mud into the eastern approach to the Islands, known as Crow Sound, and it has come to rest in that area. This was once an excellent trawling ground for flat fish, but it is now ruined by the mud.

My wife finds additional evidence of former extensive removal of sand from Salcombe in 'Kingsbridge and Salcombe, with the intermediate Estuary, historically and topographically depicted' (Kingsbridge, I8I9). The anonymous author (Abraham Hawkins) says (p. 82) that 'from the bar sand 
is dredged up and carried in barges to various parts of the shores of the estuary for manure. Such was the practice in husbandry formerly, that many persons recollect to have numbered thirtytwo (sic) of these barges on the bar at once in the years $1775-6 \& 7$. At present however they rarely exceed three or four.' Futhermore (p. IOI), from the South Sand 'large quantities of sea-sand....are...taken at will by the occupiers of farms throughout the parish of Malborough, and carried for manure. The right is founded upon an unvarying custom time immemorial, undenied and uninterrupted, and consequently cannot now be shaken.'

\section{EXPLANATION OF PLATES}

\section{Plate I}

Fig. I. Decaying Zostera banks at about low water on I8 July I935. Predicted level at Devonport $0.0 \mathrm{ft}$., Admiralty chart datum; observed level at Devonport $\mathrm{r} \cdot \mathrm{O} \mathrm{ft}$. higher. The approximate position from which the photograph was taken is indicated by the letter A in Text-fig. I. The white cross occupies the same relative position as that seen on Fig. 2 below. Photograph by M. A. Wilson.

Fig. 2. View from the same position as that from which Fig. I above was taken, photographed at dead low water on 26 March I948. Predicted level at Devonport I. $9 \mathrm{ft}$. below Admiralty chart datum; observed level at Newlyn $2.5 \mathrm{ft}$. higher than prediction for that port. The white cross marks the position from which the photograph reproduced in Pl. II, fig. 2 was taken.

\section{Plate II}

Fig. I. Collecting on a Zostera bank at about low water on I6 March 1926. Predicted level at Devonport $\mathrm{I} \cdot 7 \mathrm{ft}$. below Admiralty chart datum; observed level at Devonport $\mathrm{I} \cdot 0 \mathrm{ft}$. higher. View from position B in Text-fig. I. The white cross marks the approximate position from which was obtained the photograph reproduced as Fig. 2 below and it therefore indicates a position on the shore identical, or almost identical, with that marked by the white crosses on Pl. I, figs. I, 2 .

Fig. 2. Collecting on the same shore at about dead low water on 26 March 1948. Predicted level at Devonport I.9 ft. below Admiralty chart datum; observed level at Newlyn $2.5 \mathrm{ft}$. higher than prediction for that port. The position from which the photograph was taken is indicated by the white cross on Pl. I, fig. 2 and by the letter C in Text-fig. I. It is estimated that this position would be close to the white cross on Fig. I above. The white cross on this photograph marks the approximate position from which the photograph reproduced in Pl. IV was obtained.

\section{Plate III}

Fig. I. The Ferry House and north-west corner of Small's Cove viewed from the south-west corner (position E in Text-fig. I) on I6 March 1926.

Fig. 2. The same view as Fig. I on $2 \mathrm{I}$ May I947, I $\frac{1}{2} \mathrm{hr}$. before low water.

\section{Plate IV}

View of stony and algal covered area and of residual Zostera beds between Small's Cove and Mill Bay, I5-20 min. after dead low water on 2I May 1947. Predicted level of low water at Devonport was $0.7 \mathrm{ft}$. below Admiralty chart datum; observed level at Newlyn $2.0 \mathrm{ft}$. higher than prediction for that port but the tide had already risen about $3 \mathrm{in}$. The area enclosed by the white dots comprised the only $Z$. marina beds exposed anywhere between the ferry and the rocks at Biddlehead. The position from which this photograph was taken is indicated by a white cross in Pl. II, fig. $\mathbf{2}$, and by the letter D in Text-fig. I 


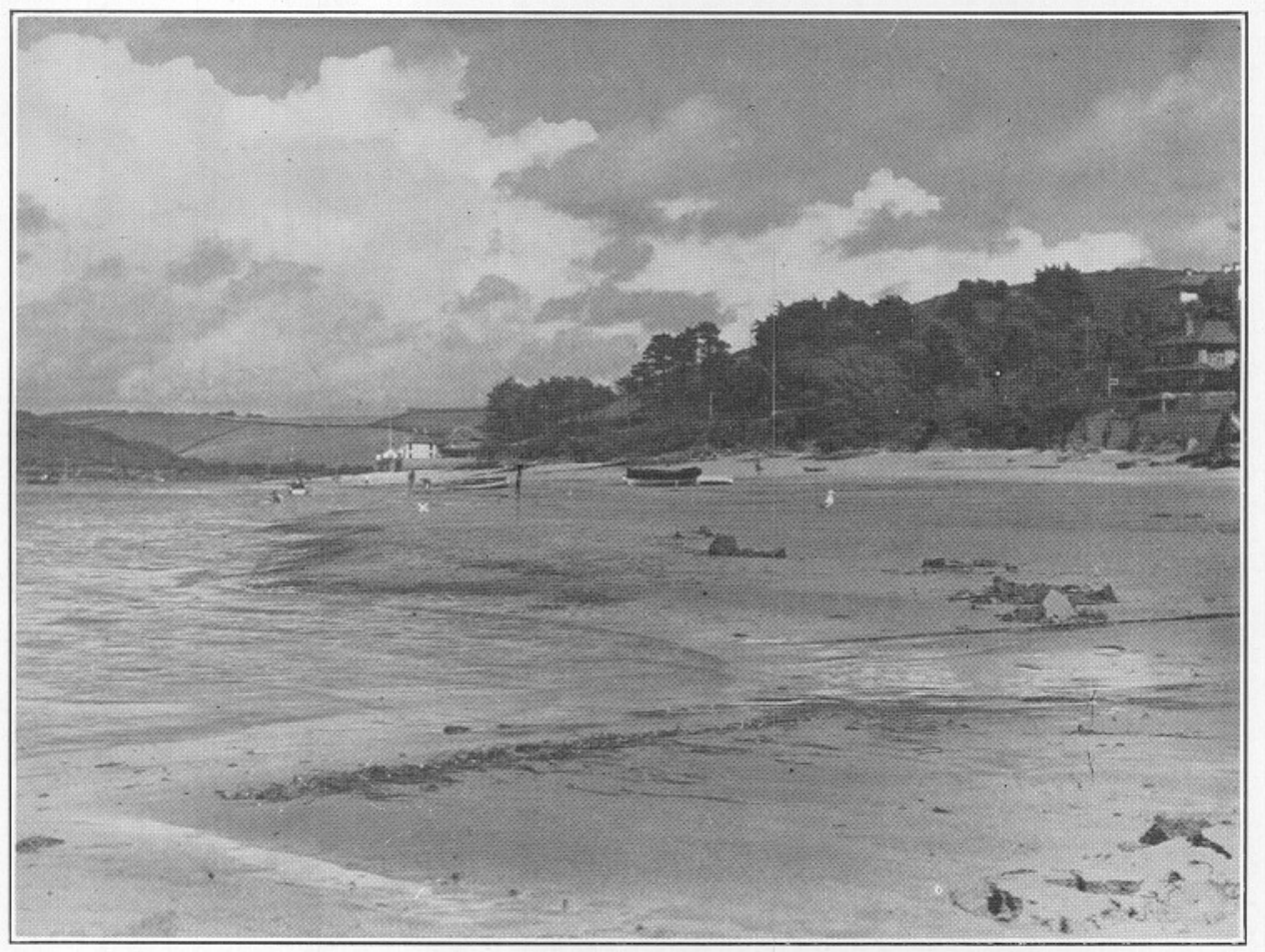

Fig, I.

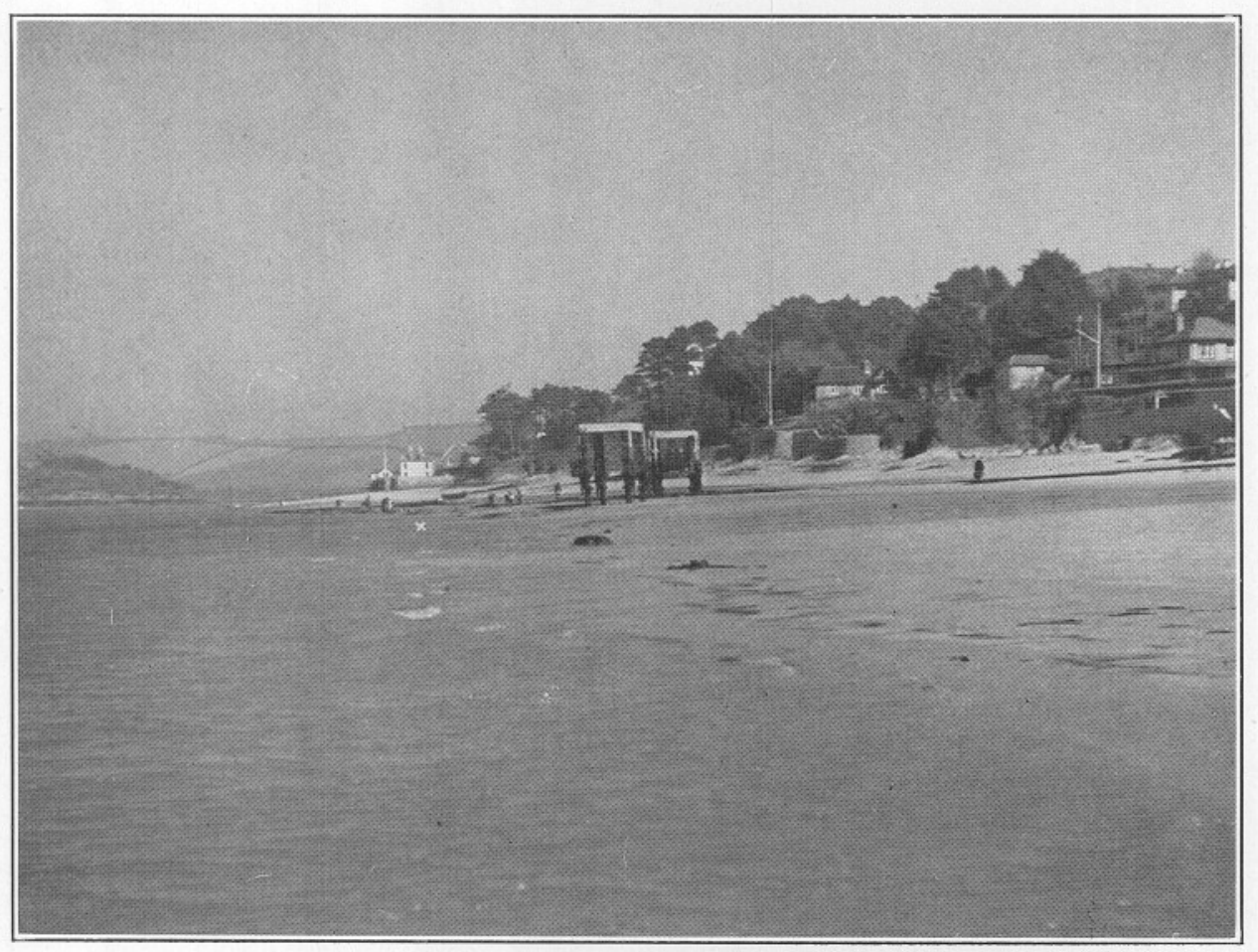

Fig. 2. 


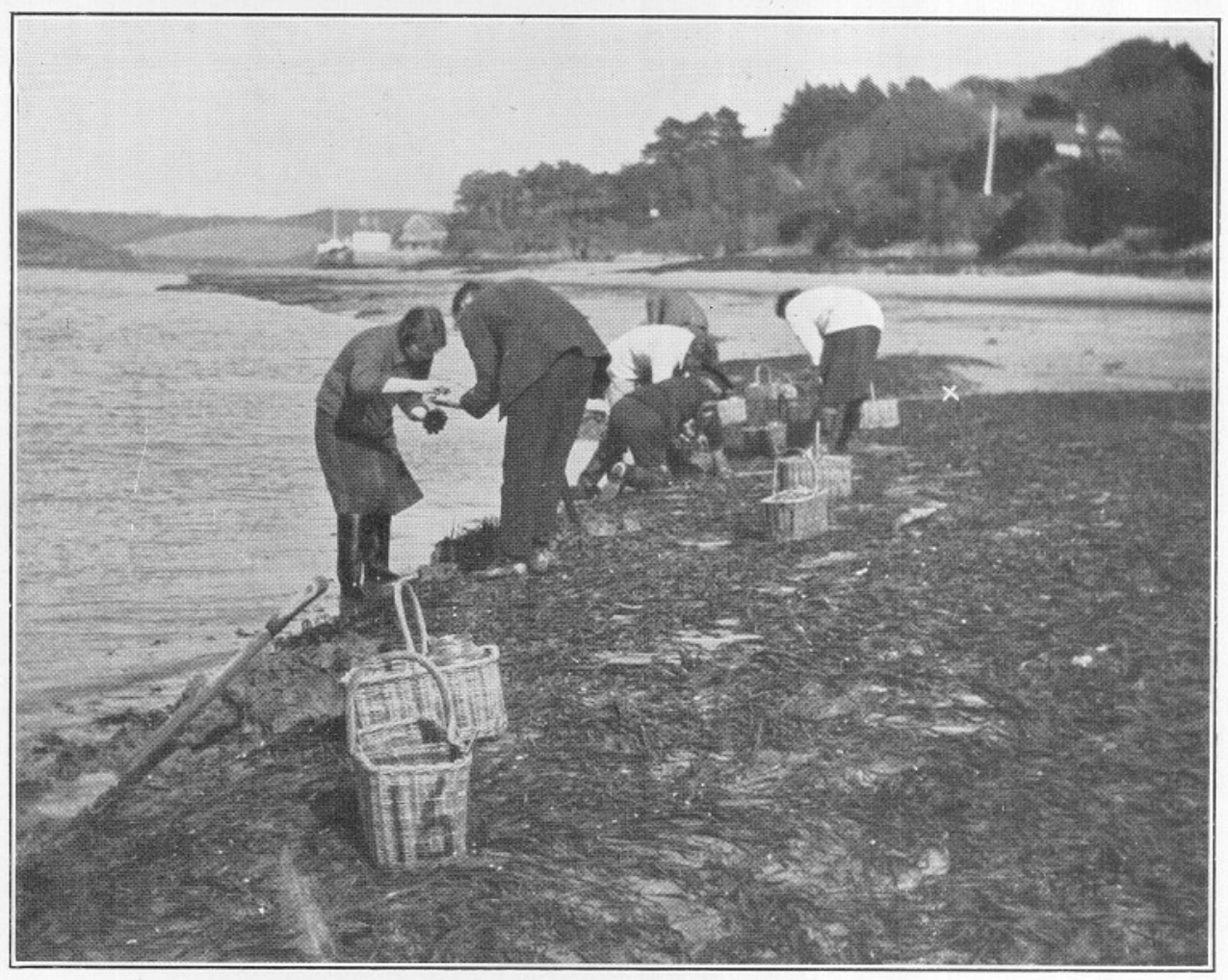

Fig. I.

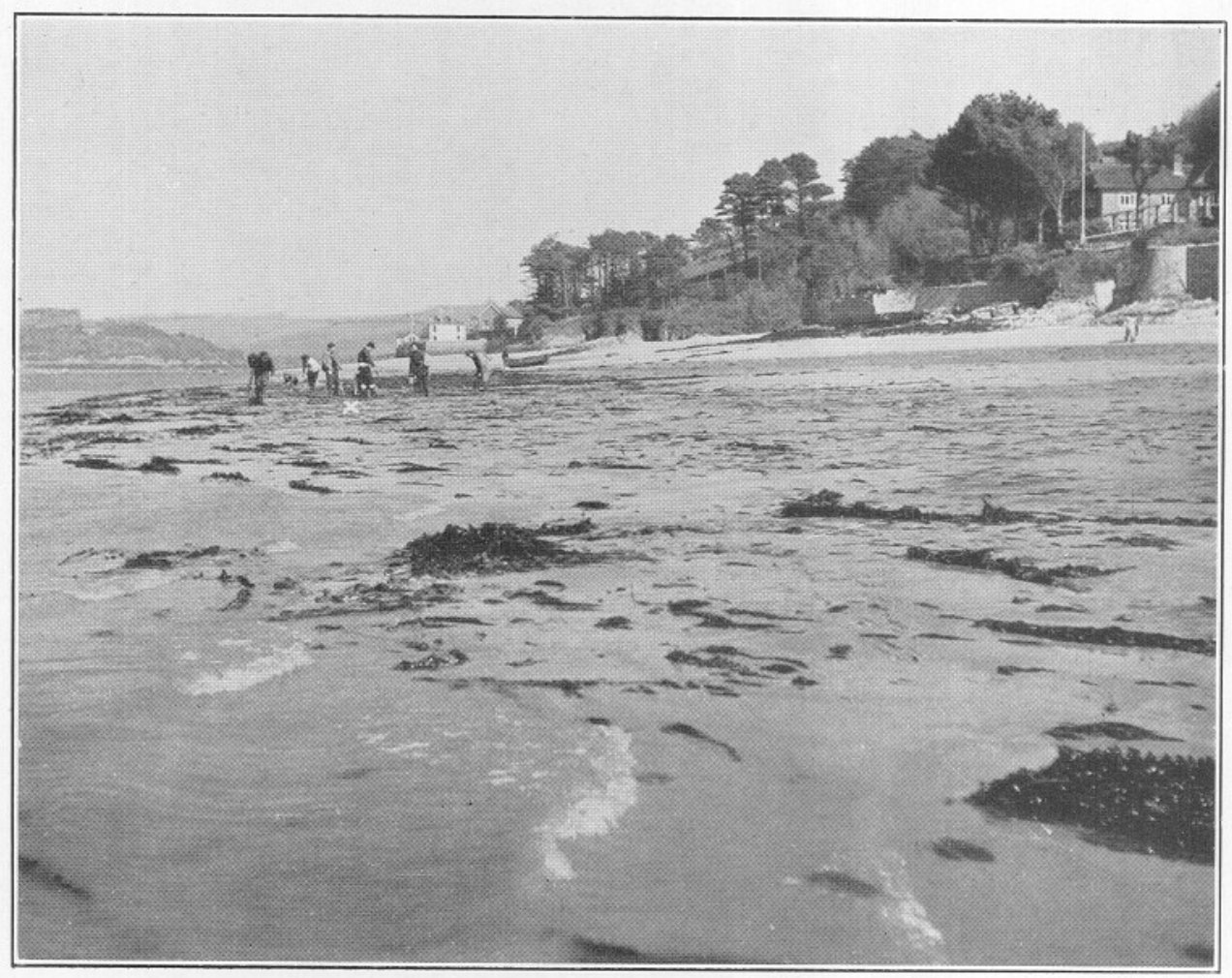

Fig. 2. 


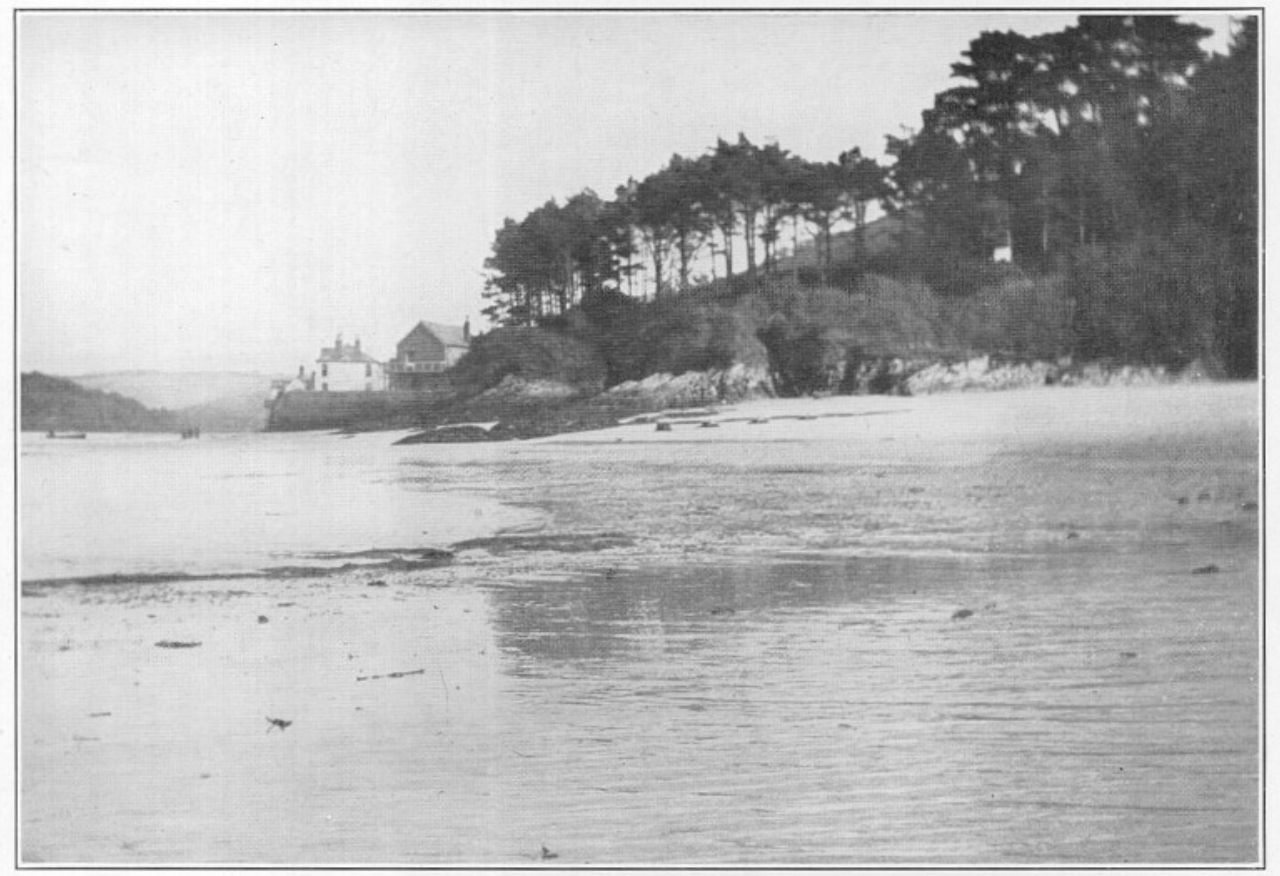

Fig. I.

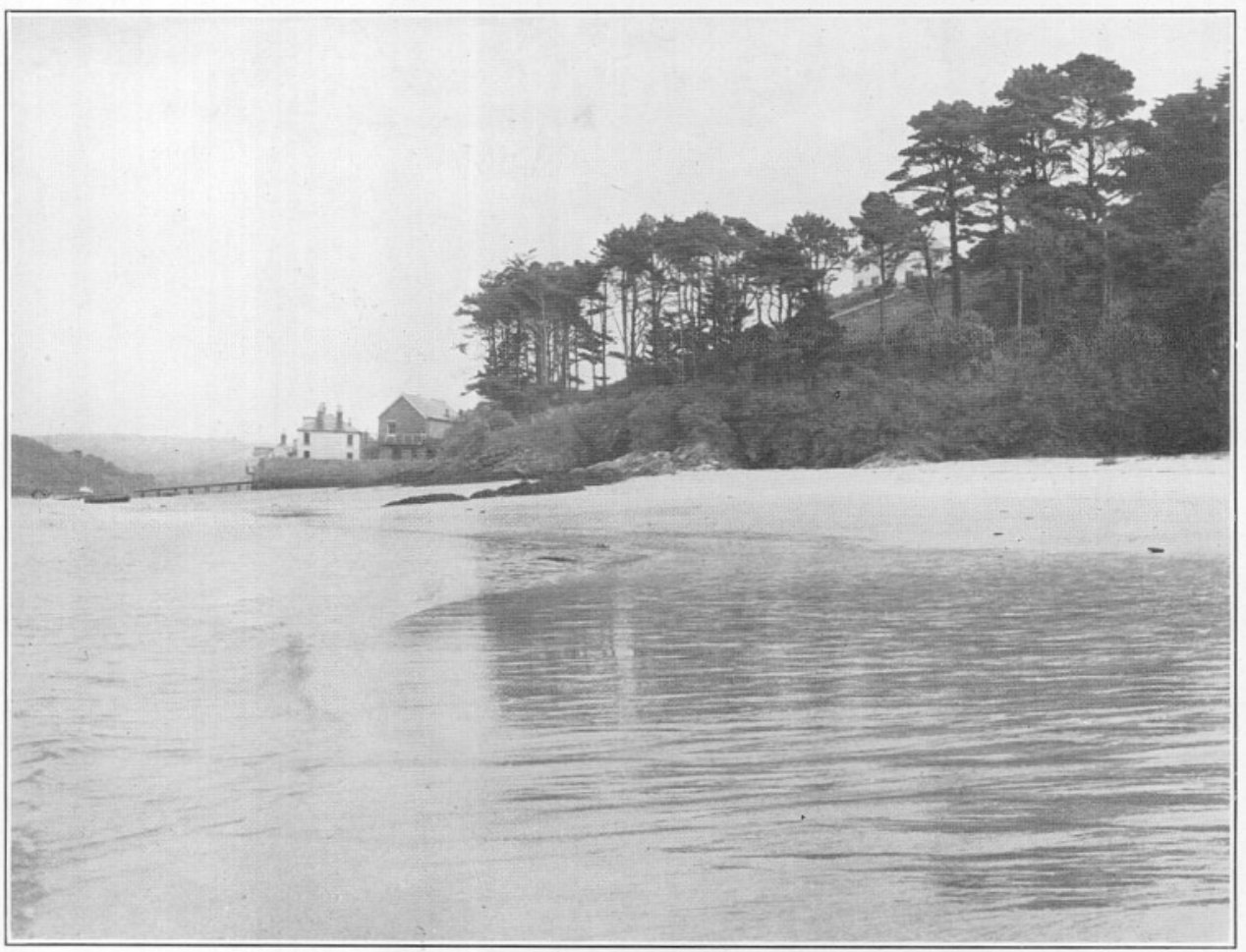

Fig. 2. 


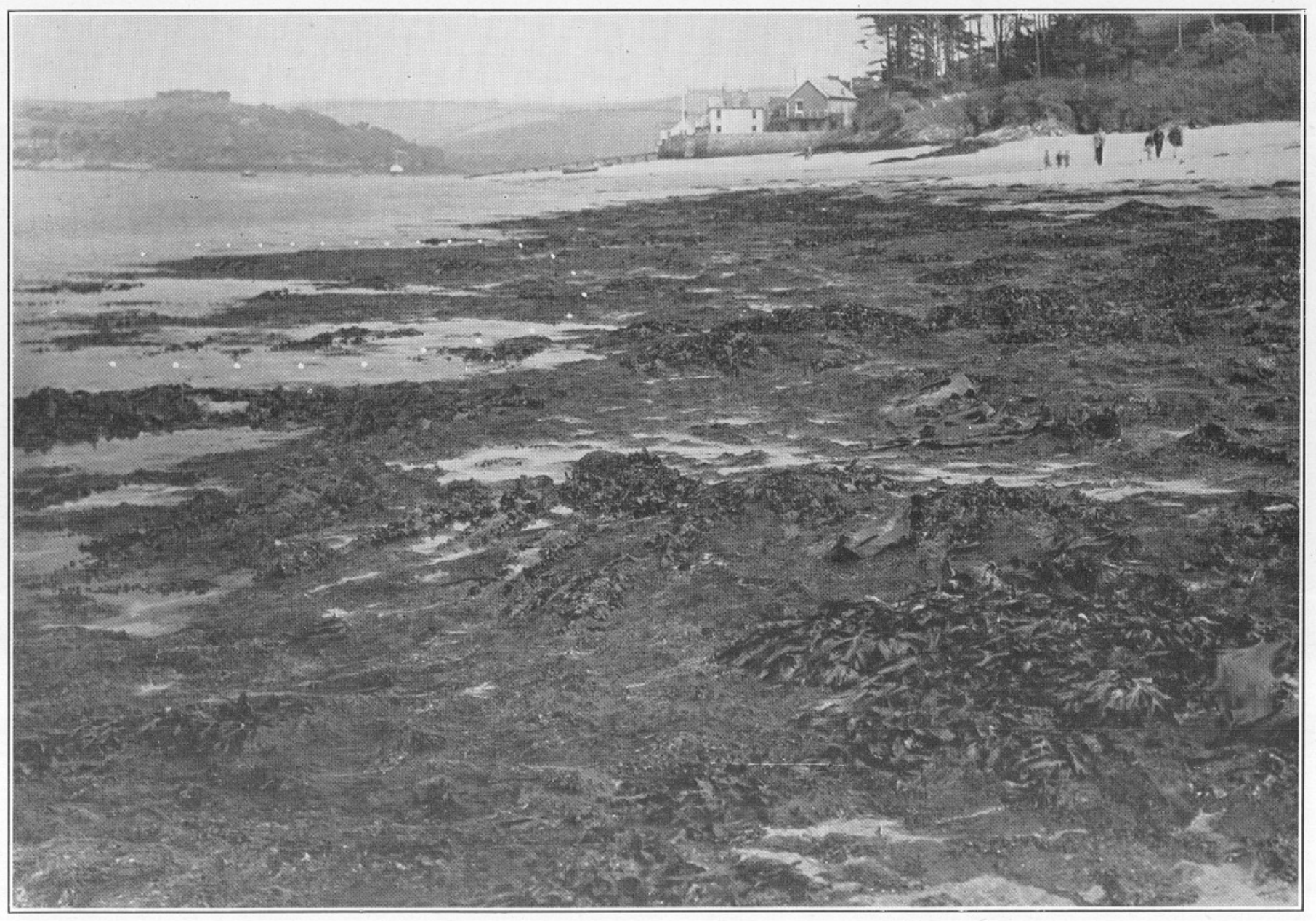

